\title{
INEQUALITIES FOR POLYNOMIALS WITH A PRESCRIBED ZERO
}

\author{
V. K. JAIN
}

Abstract. For a polynomial $p(z)$ of degree $n$, having a zero of order $k(\geqslant 1)$ at $\beta$, we have obtained

$$
\max _{|z|=1}\left|\frac{p(z)}{(z-\beta)^{k}}\right| \leqslant\left(\frac{n-k+1}{1+|\beta|}\right)^{k} \max _{1 \leqslant l \leqslant n-k+1}\left|p\left(v_{l}^{\prime}\right)\right|,
$$

$v_{1}^{\prime}, v_{2}^{\prime}, \ldots, v_{n-k+1}^{\prime}$ being the roots of $z^{n-k+1}+e^{i \gamma(n-k+1)}=0$, with $\gamma=\arg \beta(\gamma=$

0 for $\beta=0$ ), thereby extending the previously known estimate (i. e. $\max _{|z|=1}\left|\frac{p(z)}{z-\beta}\right| \leqslant$ $\frac{n}{1+\beta} \max _{1 \leqslant i \leqslant n}\left|p\left(z_{i}\right)\right|, \beta \geqslant 0, z_{1}, z_{2}, \ldots, z_{n}$ being the roots of $\left.z^{n}+1=0\right)$.

Mathematics subject classification (1991): 30C10, 30A10.

Key words and phrases: Polynomials, prescribed zero, roots.

\section{REFERENCES}

[1] A. AzIz, Inequalities for polynomials with a prescribed zero, Jour. Approx. Theory 41 (1984), 15-20.

[2] Q. I. Rahman AND Q. G. Mohammad, Remarks on Schwarz's lemma, Pac. Jour. Maths. 23 (1967), 139-142. 